\title{
Effect of Altitude on Flower Bud Differentiation and Necrosis in 'Shinko' Pears in Subtropical Climates
}

\author{
Ho-Jin Seo ${ }^{1,2}$, Young-Ook Jin ${ }^{3}$, Chin-Lung Lee ${ }^{1}$, Su-Feng Roan ${ }^{4}$, and Iou-Zen Chen ${ }^{1 *}$ \\ ${ }^{1}$ Department of Horticultural and Landscape Architecture, National Taiwan University, Taipei 106, Taiwan, ROC \\ ${ }^{2}$ Pear Research Station, National Institute of Horticultural \& Herbal Science, Naju 520-821, Korea \\ ${ }^{3}$ Department of Horticulture, Sunchon National University, Sunchon 540-950, Korea \\ ${ }^{4}$ Department of Horticulture and Biotechnology, Chinese Culture University, 55, Hwa-Kang Road, Yang-Ming-Shan, Taipei, Taiwan, ROC
}

\begin{abstract}
Time-specific responses of flower bud differentiation were investigated in 'Shinko' (Pyrus pyrifolia Nakai) pear grown at different altitudes from July through December 2013 to determine their suitability as scions in a top-grafting system. Flower bud initiation and bud necrosis were monitored on each of three sections of one-year-old shoots: terminal, middle, and basal. Flower bud differentiation started in September in the highlands of the Lishan area, and in July in the lowlands of the Zhoulan area. In Lishan, flower bud differentiation was higher in the middle and basal segments; during leaf fall, however, flower bud differentiation occurred rapidly in the terminal segment. In Zhoulan, flower buds began to differentiate from the terminal section of the shoot, and severe flower bud necrosis was noted. In July, flower buds developed normally; however, in early August, some of the buds at the basal segment showed browning. During leaf fall, some flower buds showed symptoms of necrosis with rapid and complete browning. Flower bud necrosis began at the basal segment and progressed rapidly towards middle and terminal sections. Before leaf fall, flower buds fell off when scales swelled. The terminal and middle parts of the current-year shoots, with some flower buds, collected in October or later from the Lishan area could be used as scions for top-grafting of 'Shinko' pear. Each grafting scion was a 3-5 cm shoot with one flower bud. These results suggest that scions from the terminal and middle segments of stems of 'Shinko' pear from the Lishan area can be used as scions whereas those from Zhoulan area show necrosis and might not be suitable as scions.
\end{abstract}

Additional key words: chilling requirement, Pyrus pyrifolia, scion, top-grafting

\section{Introduction}

Pears (Pyrus spp.) belong to the family Rosaceae and are generally classified into two major groups: Asian pear and European pear. Asian pears (Pyrus pyrifolia (Burm.) Nakai) are the major commercial species in China, Japan, Korea, and Taiwan (Beutel, 1990; Nee et al., 2002).

Pear production in Taiwan is concentrated mainly in Taichung and Miaoli and evenly distributed across lowand highlands. 'Heng Shan' pear is mainly produced in the lowlands such as Zhoulan township in Miaoli country and Dongshi district in Taichung country, whereas Asian pear cultivars such as 'Hosui' and 'Shinko' are cultivated in the highlands. At present, most lowland pear orchards use top-grafting cultivation method for pear production.

The top-grafting cultivation system has been widely used in Asian pears in subtropical lowlands of Taiwan since the 1980s (Byrne et al., 1995; Lin et al., 1987). The procedure involved top-grafting of dormant pear scions with welldeveloped flower buds brought from Japan or highlands of Taiwan in late fall onto 'Heng Shan' trees, a low-chilling pear cultivar with inferior fruit quality. Top-grafting cultivation is a unique pear production system worldwide. This system involves harvesting in mid-July, which is two months earlier than the harvest season for highlands and for high-chilling Asian pear cultivars, and has been commercially used to

\footnotetext{
*Comesponding author: chenyo@ntu.edu.tw
}

※ Received 15 August 2014; Revised 29 September 2014; Accepted 10 October 2014. We would like to thank the Council of Agriculture and Central Weather Bureau for providing accurate weather data during the study.

(C) 2015 Korean Society for Horticultural Science 
produce high-quality pears in lowland Taiwan. This technique had been introduced to other subtropical areas in southern Asia (Jackson, 2003; Krisanapook and Subhadrabandhu, 1995; Rakngan et al., 1995). Farmers have been benefited by this method since it improves their income.

Farmers using the top-grafting system prefer early grafting to ensure that the marketable price of the fruits is high. However, if the time of collection is inappropriate, the scions mature insufficiently, leading to unsatisfactory flower bud differentiation; this remarkably lowers the success of grafting, and thus the productivity. Previously, scions for top-grafting were obtained from high mountainous areas of central Taiwan; however, at present, about $40 \%$ of the scions are obtained from Japan because of their high quality. Two main factors affect the production efficiency of scions: dormancy and flower bud development.

In temperate-zone deciduous fruit trees, bud dormancy is a phase of development that allows the trees to survive under unfavorable conditions during winter (Faust et al., 1997). Flower bud differentiation in pear trees is influenced by the characteristics of cultivars and weather conditions of regions (Chen et al., 1997). Most terminal buds on the spurs of pear trees that grow in the highlands of Taiwan begin differentiation in late June, and development of their flower organs initiates between late July and mid-August (Fan, 1981). For different cultivars, the ratio of flower bud differentiation varies across new shoots depending on the growth potential (Nee, 1980). Flower bud differentiation in 'Hosui' cultivar in the highlands of Taiwan starts after shoot growth ceases around September (Chen et al., 1997). In contrast, the shoots of 'Hosui' pears produced in Japan stop growing in late June (Banno et al., 1985).

Currently, Taiwanese farmers prefer 'Shinko' pears that have low-chilling requirement and high quality for the top-grafting system, but the scion supply is not stable since 'Shinko' is not a major variety in Japan any more. Further, grafting of foreign scions onto domestic rootstocks involves the risk of introducing graft-transmissible exotic pathogens into Taiwan (Motoshima et al., 1983).

Therefore, this study was aimed to improve the pear scion quality by investigating flower bud differentiation and bud dormancy at different altitudes in 'Shinko' pear, a recent major cultivar for the top-grafting system in Taiwan, at different altitudes.

\section{Materials and Methods}

We used the current-year shoots of 'Shinko' pear (Pyrus pyrifolia Nakai cv. Shinko) from Lishan area (E 121.51',
$\mathrm{N} 24.16^{\prime}$, at the altitude of 2,000 m) in Taichung, and Zhoulan area (E 120.51', N 24.18', at the altitude of 500 m) in Miaoli. Between July and December 2013, one branch (40-50 cm long) per tree were collected monthly from 10 trees with similar tree vigor, and flower bud differentiation was examined under a microscope. For Zhoulan area, samples were collected only until October, since severe flower bud necrosis occurred in October, causing shortage of current-year shoots. For Lishan area, shoots were collected from fiveyear-old 'Shinko' pear trees top-grafted on 'Sinseiki' ( $P$. pyrifolia Nakai) interstock grafted on 'Callery Pears' (Pyrus calleryana Dence), with $5.0 \mathrm{~m} \times 5.5 \mathrm{~m}$ spacing in the field. For Zhoulan area, shoots were collected from top-grafted 'Shinko' pear trees in which 'Hengshan' pear (P. pyrifolia Nakai) and 'Niauli' (Pyrus lindleyi Rehder) were used as interstock and rootstock, respectively, with $6.0 \mathrm{~m} \times 6.6$ $\mathrm{m}$ spacing. In both areas, trees were trained to an overhead horizontal trellis. The trees were cultivated according to conventional agricultural practices. According to the quality grading of the pear scions imported from Japan, we collected shoots of $40-50 \mathrm{~cm}$ in length bearing 15 flower buds. Each shoot was then equally divided into three parts (terminal, middle, and basal) so that each section had five buds.

The data were analyzed using statistical analysis system (SAS; SAS Institute Inc., Cary, NC, USA), and graphs were created using Sigma Plot 12 (Systat Software, Inc., San Jose, CA, USA).

\section{Results and Discussion}

\section{Flower Bud Differentiation of 'Shinko' Pear in Lishan Area (Highland) and Zhoulan Area (Lowland)}

Flower bud differentiation in 'Shinko' pears from Lishan area began in early September. Although flower formation is known to begin at different times in Lishan and Zhoulan, the highest ratio of flower buds and the order of ratio in each segment were not different between the two areas. Flower bud differentiation in 'Shinko' pear was more advanced in older shoot tissues in both the areas. In Lishan area, for example, flower bud differentiation ratio was 1.6, 15, and $35 \%$ in the terminal, middle, and basal parts of the shoot, respectively, on September 2. However, flower bud differentiation in all the three shoot parts was almost completed around mid-November when the leaves began to fall (Fig. 1A).

In Zhoulan area, the flower bud formation began in July; it was considerably earlier than that in Lishan. The ratio of differentiated flower buds was higher in the terminal (75\%) and middle $(71 \%)$ segments than in the basal part 
(49\%; Fig. 1B). However, in Zhoulan, the ratio of flower to flower bud was not different among the three segments. The equation for the relationship between the ratio of flower to flower bud and flowering time in the two study areas was remarkably different. This indicated that the rate of flower formation differed in different areas; this could be attributed to the difference in temperature. Rakngan et al. (1995) reported that flower bud differentiation of Japanese pear occurred in May on trees grown in a heated plastic house, which is more than one month earlier than that in the open culture in Thailand. In Zhoulan and Lishan, flower bud differentiation was influenced by many external conditions (Wilkie et al., 2008), and the environmental factors that have a major influence on flower bud differentiation in pear trees reportedly include sunlight exposure, temperature, difference in temperature between day and night, and soil water content. Temperature in the highlands
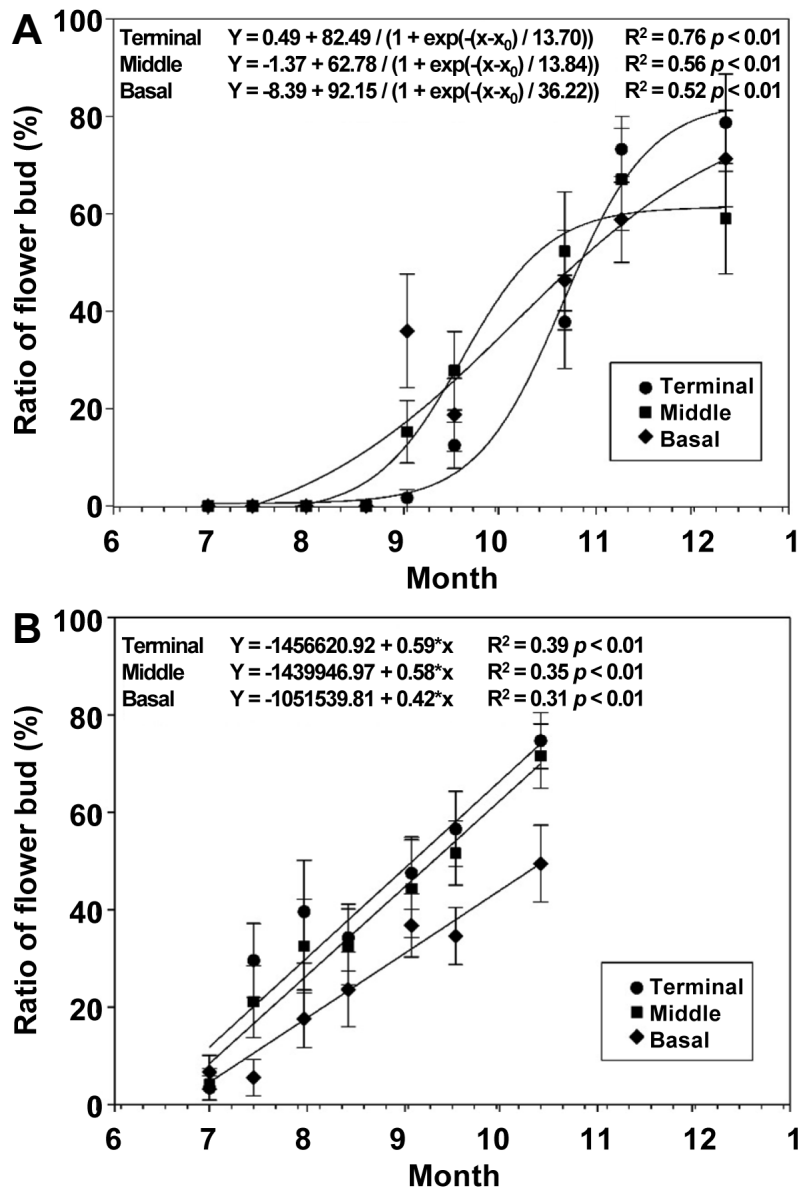

Fig. 1. Seasonal changes in the ratio of flower buds of 'Shinko' pear as a function of bud position on the shoot in (A) the highland of Lishan and (B) the lowland of Zhoulan. The values are the mean \pm SE of 10 replicates. of Lishan area is lower than that in the lowlands of Zhoulan area. Higher temperature helps buds break earlier in Zhoulan, leading to the early flower formation (Fig. 2).
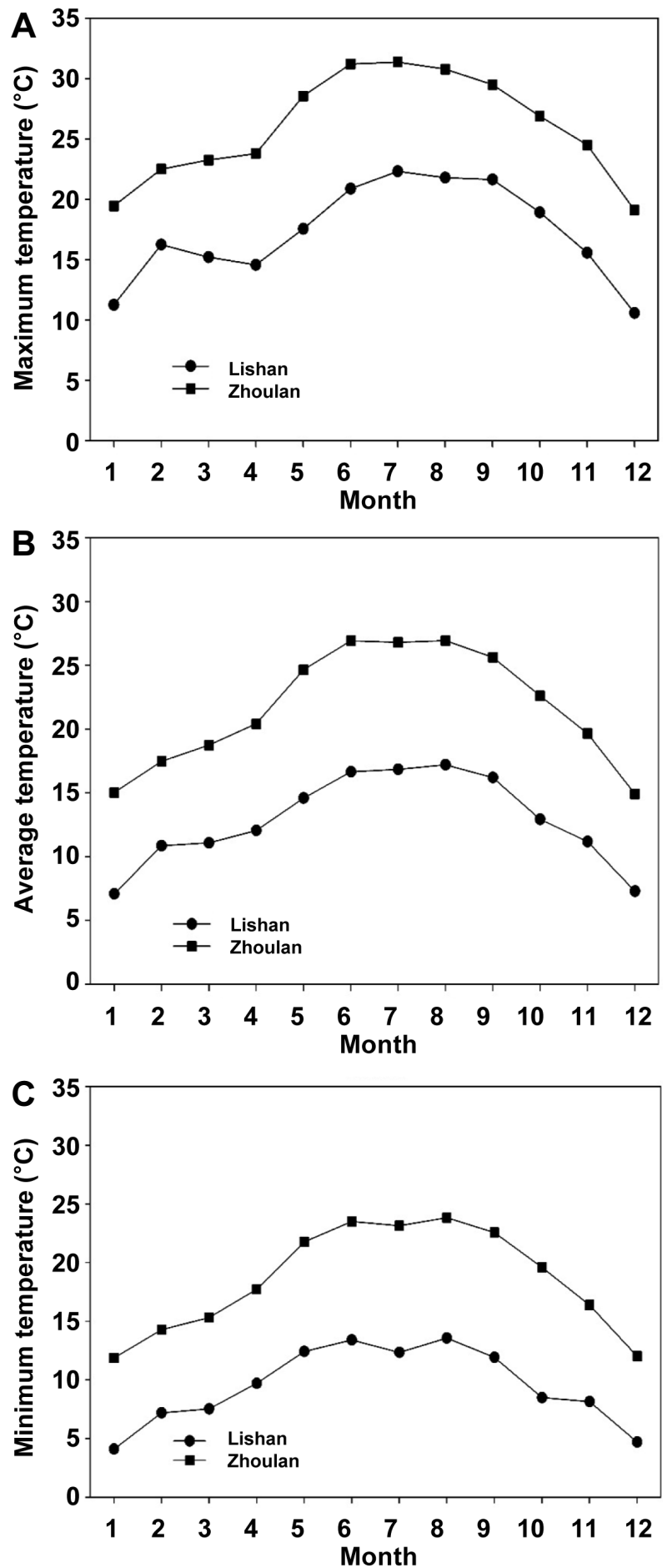

Fig. 2. Monthly means of daily maximum (A), average (B), and minimum (C) air temperature in Lishan and Zhoulan areas. Data are average from 2012 to 2013. 


\section{Flower Bud Necrosis in Zhoulan Area}

Microscopic examination of flower buds showed no necrosis in the samples from Lishan area, but flower buds sampled on August 1 from Zhoulan area showed browning (Fig. 3). In early September, severe browning was noted in $19 \%$ of the flower buds sampled, and the organ development failed to proceed in these buds. In October, browning was noted in $68 \%$ of the pear branches. The equation of the relationship between ratio of necrosis and time indicate that necrosis progressed rapidly between late August and September. This indicates that necrosis was related to temperature during this period. Necrosis was also reported in flower buds of 'Niitaka' pear; necrosis is thought to occur when buds accidentally burst without protection from intact scales at the time when leaves fall (Kim et al., 2004). Kim et al. (2006) proposed that flower bud necrosis does not occur in the dormant or flowering phase, but during flower bud differentiation. In mid-August, flower buds of 'Shinko' pears from Zhoulan area already showed browning, suggesting that bud necrosis occurred during flower bud differentiation.

Terminal flower bud of 'Niitaka' pear plant supplied with
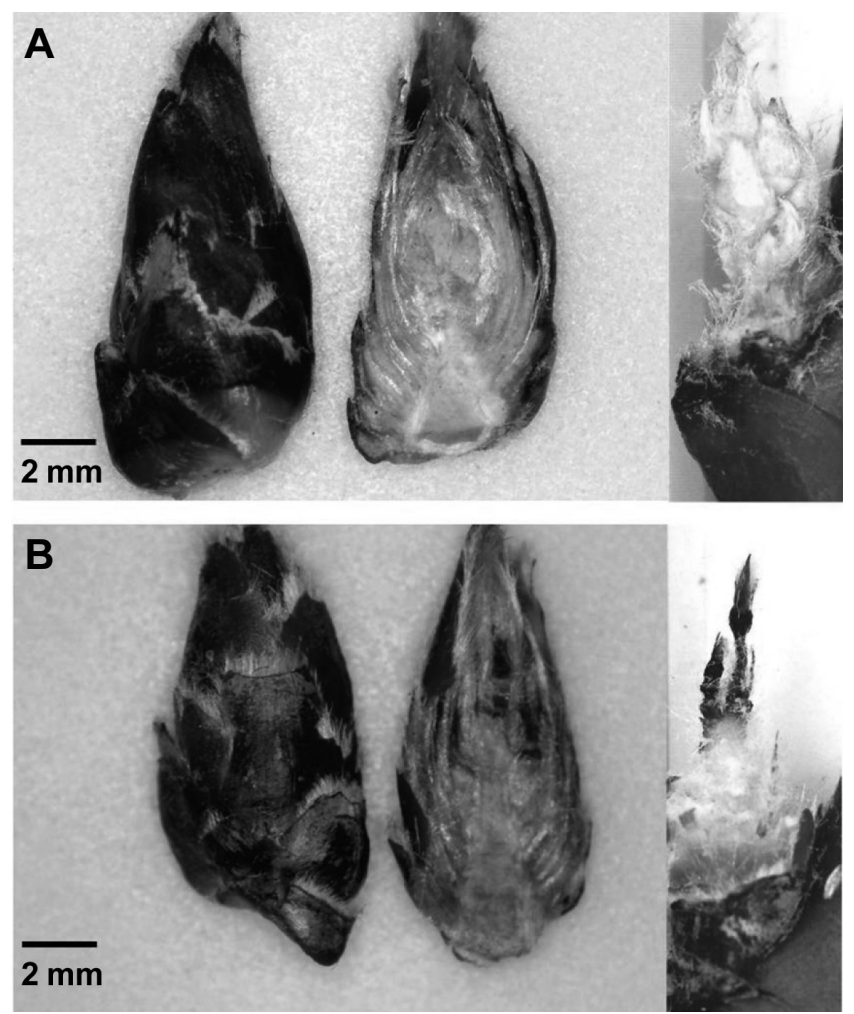

Fig. 3. Flower buds $(15 \times)$ of 'Shinko' pear collected from (A) the highland of Lishan and (B) the lowland of Zhoulan in October 2013.
$600 \mathrm{mg} \cdot \mathrm{L}^{-1}$ nitrogen would remain open and the hairs inside the scales became visible (Oh et al., 2002). This was also observed in flower buds collected in October from the Zhoulan area. The pattern of flower bud necrosis was similar to budjump described by Kingston et al. (1990) and Klinac and Geddes (1995); they suggested that necrosis occurred due to climate change during winter dormancy, damage from frost, and rainfall during the flowering period. Some adaption problems during dormancy are known to exist in Asian pears, especially those growing in regions with mild winters, such as Brazil (Petri and Herter, 2002; Petri et al., 2002), New Zealand (Klinac and Geddes, 1995; Oh and Klinac, 2003), and Thailand (Rakngan et al., 1995), or those subjected to forcing cultivation in greenhouses (Gemma, 1995).

The observation of bud necrosis, or so-called budjump, is the result of flower bud abortion, which was also reported to be about $60 \%$ in some locations in southern Brazil in 2001 (Petri et al., 2002) and more than 90\% in 1999, resulting in low number in flower burst and low production (Verissimo et al., 2002). The necrosis can be categorized into one of the adaption problems.

When necrosis occurrence rate was investigated across various shoot sections, necrosis in flower buds was found to initiate in mid-August in all shoot sections and substantially increased toward mid-October when the leaves began to fall; further, the necrosis rate was considerably slower in the basal section than in the other sections ( $48 \%$ vs. $70 \%$ ), but there was no statistical difference in the necrosis rate across different sections in mid-August (Fig. 4). Numerous causes for flower bud necrosis in Asian pear trees have been proposed. In 2006, some physiological disorders in 'Shinsui' pear were noticed in Southwestern Japan and in the greenhouse cultivation in Fukuoka, and increment in temperature during dormancy was known to be the major factor for necrosis in flower buds in both buds and shoots (Honjo, 2007). Necrosis intensity and timing are thought to be related to the amount of chilling accumulation and the occurrence of thermal fluctuations (Marafon et al., 2010; Yamamoto et al., 2010). Nutritional factors, flower development, and physiological stress could also be the possible causes for necrosis (Kim et al., 2006; Verissimo et al., 2004). In this study, however, the symptoms of necrosis occurred before buds entered dormancy, suggesting that thermal fluctuations during flower development might be a cause of the necrosis. Therefore, further studies are warranted to determine the actual reason for flower bud necrosis in 'Shinko' pears from Zhoulan area and the effect of thermal fluctuations on flower development. 


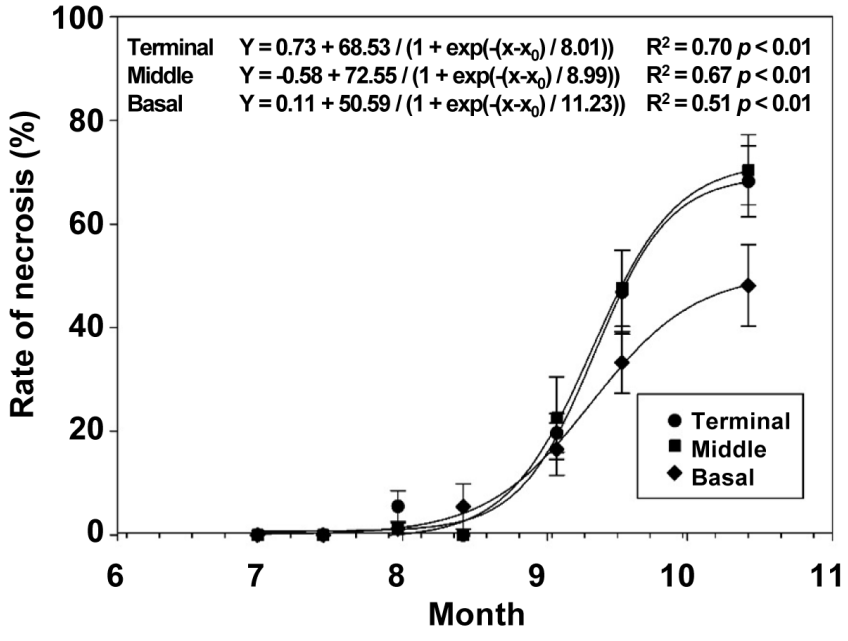

Fig. 4. Seasonal changes in the percentage of necrosis in flower buds of 'Shinko' pear from the lowland of Zhoulan area as a function of bud position on the shoot. The values are the mean \pm SE of 10 replicates.

The results of this study showed that scion wood with good flower bud differentiation capacity can be acquired from 'Shinko' pear trees grown in the highlands of Taiwan, provided they are collected in September or later. However, the 'Shinko' pear scions from the lowlands of Zhoulan area showed the symptoms of bud necrosis that developed mainly during flower bud differentiation, indicating that the scion wood from the lowlands might not be suitable.

\section{Literature Cited}

Banno, K., S. Hayashi, and K. Tanabe. 1985. Relationships between flower bud formation and endogenous growth regulators in Japanese pear cultivars (Pyrus serotina Rehd.). J. Japan. Soc. Hort. Sci. 54:15-25.

Beutel, J.A. 1990. Asian pears, p. 304-309. In: J. Janick and J.E. Simon (eds.). Advances in new crops. Timber Press, Portland, OR, USA.

Byrne, D.H., S.K. Ou, and J.B. Storey. 1995. Annual grafting of Nashi pear in low chill areas of Taiwan. Fruit Varieties J. 49:103-106.

Chen, C., C.C. Huang, R.W. Chio, and C.C. Huang. 1997. The effect of shoot bending and other cultivation practices on the lateral flower bud formation of 'Hosui' pear grown in Taiwan highland area, p. 187-196. In: L.J. Chang and R.W. Chen (eds.). Proceedings of a symposium on enhancing competitiveness of fruit industry II. Taichung District Agricultural Improvement Station, Chunghua, Taiwan.

Fan, N.T. 1981. Studies on the flower-bud differentiation of apple and pear in Taiwan. I. Morphological change in bud. Nchu Hort. 6:9-16.
Faust, M., A. Erez, L.J. Rowland, S.Y. Wang, and H.A. Norman. 1997. Bud dormancy in perennial fruit trees: Physiological basis for dormancy induction, maintenance and release. HortScience 32:623-629.

Gemma, H. 1995. Dormancy breaking in Japanese pear grown in a heated greenhouse. Acta Hortic. 395:57-68.

Honjo, H. 2007. Effects of global warming on dormancy and flowering behavior of temperate fruit crops in Japan. Hort. Res. Jpn. 6:1-5.

Jackson, J.E. 2003. Biology of apples and pears. Cambridge Univ. Press, Cambridge, UK. p. 488.

Kim, J.K., S.H. Kim, Y.T. Yim, and H.H. Seo. 2004. Shoot growth and mineral concentration in 'Niitaka' pear trees with flower bud necrosis. Kor. J. Hort. Sci. Technol. 22:444-447.

Kim, J.K., S.H. Kim, Y.T. Yim, and H.H. Seo. 2006. Anatomical feature, sugar, carbohydrate, and hormone content of normal and abnormal flower buds in 'Niitaka' pear trees. Kor. J. Hort. Sci. Technol. 24:354-358.

Kingston, C.M., D.J. Klinac, and C.W van Epenhuijsen. 1990. Flower bud disorders of nashi (Pyrus serotina) grown in New Zealand. New Zealand J. Crop Hort. Sci. 18:157-159.

Klinac, D.J. and B. Geddes. 1995. Incidence and severity of the flower bud disorder 'budjump' on nashi (Pyrus serotina) grown in the Waikato region of New Zealand. New Zealand J. Crop Hort. Sci. 23:185-190.

Krisanapook, K. and S. Subhadrabandhu. 1995. Effect of some practices and hydrogen cyanamide on bud break of 'Shinseiki' pear. Acta Hortic. 395:149-152.

Lin, H.S., C.L. Lee, and C.O. Lin. 1987. Production of high chilling Asian pear in Taiwan's lowland. Acta Hortic. 199:101-108.

Marafon, A.C., F.G. Herter, F.J. Hawerroth, and A.S. Silva. 2010. Occurrence time and intensity of flower bud necrosis and inflorescence duplication in pear trees 'Housui' (Pyrus pyrifolia (Burm.) Nak.) during the dormancy period in Pelotas - RS, Brazil. Acta Hortic. 872:97-100.

Motoshima, S., M. Kato, T. Nishio, and T. Kobayashi. 1983. Sap-transmissible viruses detected from imported pear plants. Res. Bull. Plant Prod. Ser., Japan 19:29-37.

Nee, C.C. 1980. Studies on the growth and flower bud differentiation of pear trees at low altitude district of Taiwan. Nchu Hort. 5:38-41.

Nee, C.C., C.H. Tsai, and D.D. Anstine. 2002. Asian pear germplasm future trends and current research in the industry. Acta Hortic. 587:61-69.

Oh, S.D. and D. Klinac. 2003. Relationship between incidence of floral bud death and temperature fluctuation during winter in Japanese pear (Pyrus pyrifolia cv. Hosui) under New Zealand climate conditions. J. Kor. Soc. Hort. Sci. 44:162-166.

Oh, S.D., S.N. Jin, and H.J. Lee. 2002. Growth, leaf nitrogen contents, and nitrate reductase activity of pear (Pyrus pyrifolia cv. Niitaka) trees as affected by different levels of nitrogen supply. J. Kor. Soc. Hort. Sci. 43:433-438. 
Petri, J.L. and F.G. Herter. 2002. Nashi pear (Pyrus pyrifolia) dormancy under mild temperature climate conditions. Acta Hortic. 587:353-361.

Petri, J.L., G.B. Leite, and Y. Yasunobu. 2002. Studies of the causes of floral bud abortion of Japanese pear (Pyrus pyrifolia) in Southern Brazil. Acta Hortic. 587:375-380.

Rakngan, J., H. Gemma, and S. Iwahori. 1995. Flower bud formation in Japanese pear trees under adverse conditions and effects of some growth regulators. Jpn. J. Trop. Agr. 39:1-6.

Verissimo, V., F.G. Herter, A.C. Rodrigues. J.P. Gardin, and J.B. Silva. 2004. Characterization of pear flower bud (Pyrus sp.) and the relation with flower bud abortion. Rev. Bras. Frutic.
26:193-197.

Verissimo, V., J.P. Gardin, R. Trevisan, and F.G. Herter. 2002. Morphological and physical parameters of flower buds of trees of two Japanese pear cultivars grown at three different areas of Southern Brazil, and their relationship with flower bud abortion intensity. Acta Hortic. 587:381-387.

Wilkie, J.D., M. Sedgley, and T. Olesen. 2008. Regulation of flower initiation in horticultural trees. J. Exp. Bot. 59:3215-3228.

Yamamoto, R.R., Y. Sekozawa, S. Sugaya and H. Gemma. 2010. Influence of chilling accumulation time on "flower bud abortion" occurrence in Japanese pear grown under mild winter conditions. Acta Hortic. 872:69-76. 